\title{
Hydrogenation of Acetophenone in the Presence of Ru Catalysts Supported on Amine Groups Functionalized Polymer
}

\author{
Dorota Duraczyńska $\cdot$ Alicja Drelinkiewicz • \\ Elżbieta Bielańska • Ewa M. Serwicka • \\ Lidia Lityńska-Dobrzyńska
}

Received: 19 July 2010/Accepted: 3 September 2010/Published online: 24 September 2010

(C) The Author(s) 2010. This article is published with open access at Springerlink.com

\begin{abstract}
Liquid phase hydrogenation of acetophenone (ACT) is studied over ruthenium catalysts $(1-4 \mathrm{wt} \% \mathrm{Ru})$ supported on gel-type methacrylate-styrene resin (FCN) functionalized with $\mathrm{C}=\mathrm{O},-\mathrm{NH}$, and $-\mathrm{NH}_{2}$ groups. Microscopic studies (SEM, STEM) show that the nature of Ru particles depends on the level of Ru doping. At low $\mathrm{Ru}$ content (1-2 wt \%) ruthenium nano-clusters are formed, while at $4 \mathrm{wt} \% \mathrm{Ru}$, metal crystallites of few nanometers in size are observed. Catalytic reactions are performed at mild conditions (atmospheric pressure of hydrogen, $40{ }^{\circ} \mathrm{C}$ ) in biphasic isooctane-water $\left(\mathrm{IO} / \mathrm{H}_{2} \mathrm{O}\right)$ solvent system, and, for comparison, in a single component solvent (isooctane or ethanol). The use of biphasic $\mathrm{IO} / \mathrm{H}_{2} \mathrm{O}$ solvent system results in a dramatic improvement of selectivity. The hydrogenation of $\mathrm{C}=\mathrm{O}$ in acetophenone dominates over the hydrogenation of aromatic ring, yielding 1-phenylethanol with ca. $80 \%$ selectivity. Ru/FCN catalysts exhibit higher selectivity than the reference $\mathrm{Ru} / \mathrm{Al}_{2} \mathrm{O}_{3}$. This is tentatively assigned to the steric effects induced by the polymer network on migrating reactant molecules. Advantageous influence of biphasic $\mathrm{IO} / \mathrm{H}_{2} \mathrm{O}$ solvent system has been attributed to the solvation of phenyl ring of acetophenone by non-polar isooctane, which facilitates the interaction with the catalyst surface via carbonyl group and leads to the preferential reduction to 1-phnenylethanol.
\end{abstract}

D. Duraczyńska · A. Drelinkiewicz $(\bowtie) \cdot$ E. Bielańska ·

E. M. Serwicka

Institute of Catalysis and Surface Chemistry, Polish Academy

of Sciences, ul. Niezapominajek 8, 30-239 Krakow, Poland

e-mail: ncdrelin@cyf-kr.edu.pl

L. Lityńska-Dobrzyńska

Institute of Metallurgy and Materials Science, Polish Academy

of Sciences, ul. Reymonta 25, 30-059 Krakow, Poland
Keywords Functional polymer - Ruthenium . Hydrogenation - Acetophenone

\section{Introduction}

Catalytic hydrogenation of aromatic ketones to phenyl alcohols constitutes an important aspect of organic synthesis, affording key intermediates in the production of fine chemicals and drugs. The hydrogenation of acetophenone (ACT) is a typical example of this type of reactions. Selective hydrogenation of ketones can be achieved with homogeneous catalysts and most of hydride reduction of ACT exclusively gives 1-phenylethanol, as described in recently published reviews [1-3]. Unfortunately, the problems in products separation, recovery and reuse of catalysts create demand for heterogeneous catalysts. A number of studies have already been directed to hydrogenation of ACT using heterogeneous $\mathrm{Pt}, \mathrm{Pd}, \mathrm{Rh}$, and $\mathrm{Ru}$ catalysts in reactions carried out under liquid- or gas-phase conditions [4-13]. Selective hydrogenation of ACT to 1-phenylethanol (PE) is complicated by the fact that different side reactions may take place. In consequence, achieving high selectivity to 1-phenylethanol, the desired product, is a challenging issue. On $\mathrm{Pt}$ and $\mathrm{Rh}$ catalysts the comparable rates of $\mathrm{C}=\mathrm{O}$ and phenyl ring hydrogenations result in a mixture of various products $[6$, $7,9,10]$. An exception is $\mathrm{Pt} / \mathrm{TiO}_{2}$ catalyst which exhibit high and selective ability for $\mathrm{C}=\mathrm{O}$ activation due to the presence of active centers formed as the result of strong metal support interactions [14-16]. Palladium supported catalysts, besides being highly reactive toward $\mathrm{C}=\mathrm{O}$ hydrogenation to $\mathrm{C}-\mathrm{OH}$, they catalyze the hydrogenolysis of $\mathrm{C}-\mathrm{OH}$ to give ethylbenzene as a final product $[13,17$ 20]. Ruthenium supported catalysts are also tested in 
hydrogenation of ACT because of their high ability to hydrogenate carbonyl group in the vicinity of conjugated and isolated double bonds [11, 12, 21, 22]. Indeed, in the case of citral and cinamaldehyde a highly selective hydrogenation to the corresponding unsaturated alcohols is observed [11]. However, when Ru catalysts are used in hydrogenation of aromatic aldehydes or ketones, such as acetophenone, they exhibit comparable reactivity toward hydrogenation of carbonyl group and aromatic ring of ACT $[12,21,22]$. In hydrogenation of ACT on Ru-catalysts two alternative reaction pathways are observed (Scheme 1) [11]. One involves hydrogenation of $\mathrm{C}=\mathrm{O}$ group to give $\mathrm{C}-\mathrm{OH}$ in 1-phenylethanol $(\mathrm{PE})$, the other leads to hydrogenation of aromatic ring of ACT to form cyclohexyl methyl ketone (CMK). Both products, PE and CMK, undergo further but slower hydrogenation to 1cyclohexylethanol (CE) as a final product. Other products, such as ethylbenzene, benzene, cyclohexene and cyclohexane are also formed, but in much smaller quantities [12]. In order to enhance selectivity of $\mathrm{C}=\mathrm{O}$ hydrogenation an appropriate support or modification of Ru-catalysts with metal additives are needed. Results obtained by Cerveny et al. [12] and by Wismeijer et al. [22] show that among Ru-catalysts supported on $\mathrm{Al}_{2} \mathrm{O}_{3}, \mathrm{SiO}_{2}, \mathrm{C}$ and $\mathrm{TiO}_{2}$, the best efficiency in selective formation of $\mathrm{PE}$ is observed for $\mathrm{Ru} / \mathrm{TiO}_{2}$ catalyst. The effect is assigned to the possible activation of the carbonyl double bond by $\mathrm{Ti}^{3+}$ cations, formed on the $\mathrm{TiO}_{2}$ support [22]. Also, the promotion of silica supported $\mathrm{Ru}$ catalysts with $\mathrm{Cr}$ ions enhances the selective reduction of $\mathrm{C}=\mathrm{O}$, but the overall activity decreases [23]. The selectivity increase is attributed to the strong interaction of the oxygen atom of $\mathrm{C}=\mathrm{O}$ group with the $\mathrm{Cr}$ ions. In the present work hydrogenation of ACT is studied on Ru-supported catalysts using biphasic solvent system composed of less polar isooctane and polar water $\left(\mathrm{IO} / \mathrm{H}_{2} \mathrm{O}\right)$. According to the literature, in biphasic $\mathrm{IO} / \mathrm{H}_{2} \mathrm{O}$ solvent system a variety of catalytic reductions can effectively proceed under mild conditions (ca. $50{ }^{\circ} \mathrm{C}$, atmospheric pressure of hydrogen) and their

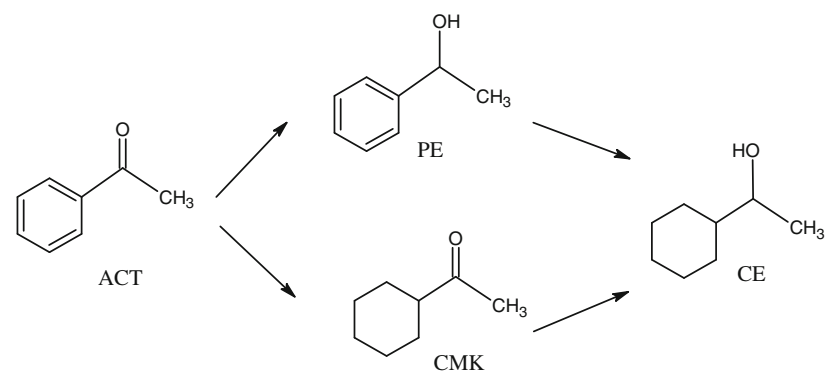

Scheme 1 Reaction pattern of acetophenone hydrogenation in the presence of Ru catalysts selectivity can be modified [24-27]. Thus, Marques et al. [24] demonstrate that hydrogenation of propiophenone on $\mathrm{Pd} / \mathrm{C}$ catalyst in conventional ethanol solvent produces propylbenzene as the final product, while in the biphasic $\mathrm{IO} / \mathrm{H}_{2} \mathrm{O}$ system propiophenone is almost selectively reduced to 1-phenyl-1-propanol [24]. In contrast, on Pt/C catalyst and in $\mathrm{IO} / \mathrm{H}_{2} \mathrm{O}$ system, the hydrogenation of acetophenone and propiophenone proceeds towards the full reduction products, ethyl benzene and ethyl cyclohexane, respectively $[25,26]$. Biphasic $\mathrm{IO} / \mathrm{H}_{2} \mathrm{O}$ system is also successfully used for enantioselective hydrogenation of ACT in the presence of cinchona-modified $\mathrm{Pt} / \mathrm{C}$ catalyst [27]. Moreover, our preliminary catalytic data demonstrate the advantage of biphasic $\mathrm{IO} / \mathrm{H}_{2} \mathrm{O}$ solvent system in hydrogenation of ACT in the presence of Ru-catalysts supported on methacrylate-styrene gel-type resin (FCN) (Scheme 2). The FCN polymer is functionalized with $\mathrm{C}=\mathrm{O},-\mathrm{NH}$, and $-\mathrm{NH}_{2}$ groups and is used for the preparation of palladium catalysts with finely dispersed $\mathrm{Pd}-$ nanoparticles [28, 29]. Our previous results show that functional groups of FCN resin, and in particular the Ncontaining ones participate in the bonding of $\mathrm{Pd}, \mathrm{Ru}-$ species via filling metal coordination sphere [28-30]. Functional groups may also affect the electron properties of active centers and in consequence catalytic properties of studied Ru/FCN samples.

Homogeneous $\mathrm{Ru}(\mathrm{III})$ complexes with nitrogen and oxygen-containing ligands like diamine, diamino alcohols, amine carboxylic etc. are capable of catalyzing various reactions, oxidation, hydrogenation and hydrogen transfer reactions. Traditionally, insoluble polymer resins such as divinylbenzene, cross-linked polystyrene have been studied as supports for heterogenization of such catalytically active complexes. Other, but more convenient way to prepare polymer-anchored catalytically active metal species is the use of polymers that are functionalized with appropriate coordinating ligands, such as $\beta$-diketones $(\mathrm{O}, \mathrm{O})$, dipyridyl amine $(\mathrm{N}, \mathrm{N})$, diphosphine $(\mathrm{P}, \mathrm{P})$ etc. For example, $\mathrm{Ru}$ immobilized on poly(4-vinylpyridine) is reported to be an efficient catalyst for selective hydrogenation of aromatic ring of quinoline [31]. Ru supported on potassium methacryloyl ethylene sulphonate resin is found to be efficient in partial hydrogenation of benzene [32], and $\mathrm{Ru}$ immobilized by chloromethylated styrenedivinyl benzene copolymer functionalized by glycine is effective for hydrogenation of nitrobenzene [33]. This

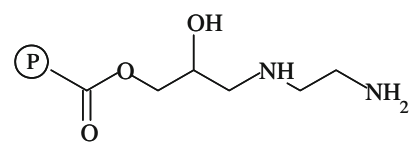

Scheme 2 The simplified structure of FCN resin 
method, based on the usage of polymer functionalized with coordinating ligands is also applied in the present work.

Here, the role of biphasic $\mathrm{IO} / \mathrm{H}_{2} \mathrm{O}$ solvents system in hydrogenation of ACT is studied using $\mathrm{Ru} / \mathrm{FCN}$ catalysts of various $\mathrm{Ru}$ content. For comparison, the reaction is also studied in the presence of $\gamma-\mathrm{Al}_{2} \mathrm{O}_{3}$ supported $\mathrm{Ru}$.

\section{Experimental}

\subsection{Materials}

Acetophenone is purchased from Sigma-Aldrich, 1-phenylethanol, 1-cyclohexylethanol, cyclohexyl methyl ketone are from Fluka, and isooctane is from POCH. All chemicals are used as purchased.

\subsection{Preparation of Catalysts}

The FCN resin (3\% crosslinking degree) (77 wt $\%$ styrene, $2.78 \mathrm{wt} \% \mathrm{~N}$ content) [28] swells very well in THF and this solvent is used as a medium during the preparation of Ru-composites (1, 2 and $4 \mathrm{wt} \% \mathrm{Ru})$ according to the previously described procedure [30]. Thus, FCN resin preswollen in THF is treated with appropriate amount of aqueous solution of $\mathrm{RuCl}_{3}$ under slow mixing up to the complete incorporation of ruthenium species. After washing and drying in air, the as-received composites are reduced by $\mathrm{NaBH}_{4}$ solution in THF: $\mathrm{CH}_{3} \mathrm{OH}$ (9:1 volume ratio) using 10-fold excess. The resulting black Ru-polymer beads are washed with THF/acetone several times and dried in air. $2 \% \mathrm{Ru} / \mathrm{Al}_{2} \mathrm{O}_{3}$ catalyst $\left(\gamma-\mathrm{Al}_{2} \mathrm{O}_{3}\right.$, BET surface area $155 \mathrm{~m}^{2} / \mathrm{g}$, particles ca. $\left.100 \mu \mathrm{m}\right)$ is prepared by impregnation method using aqueous solution of $\mathrm{RuCl}_{3}$, followed by reduction with $\mathrm{NaBH}_{4}$ [30].

\subsection{Characterization Methods}

The reduced $\mathrm{Ru} / \mathrm{FCN}$ catalysts are characterized by XRD, SEM and STEM techniques. X-ray diffraction patterns (XRD) are obtained with a Siemens D5005 diffractometer using $\mathrm{Cu} \mathrm{K} \alpha$ radiation. Morphology of catalysts is studied by means of Field Emission Scanning Electron Microscope JEOL JSM-7500 F equipped with the X-ray energy dispersive (EDS) system. The secondary electron detector provides SEI images and back scattered electron detector provides BSE (COMPO) micrographs. K575X Turbo Sputter Coater is used for coating the specimens with chromium (deposited film thickness-20 nm). STEM studies are performed on FEI Tecnai $\mathrm{G}^{2}$ transmission electron microscope at $200 \mathrm{kV}$ equipped with EDAX EDX and HAADF/STEM detectors.

\subsection{Hydrogenation Experiments}

Hydrogenation experiments are carried out in an agitated batch glass reactor at constant atmospheric pressure of hydrogen and temperature of $40{ }^{\circ} \mathrm{C}$ [30]. A biphasic solvent system, composed of isooctane and water $(2 \times$ distilled) in $1: 1$ volume ratio is used. In a typical hydrogenation test the concentration of ACT is $0.137 \mathrm{~mol} /$ $\mathrm{dm}^{3}$ (referred to isooctane phase) and the concentration of catalyst is $10 \mathrm{~g} / \mathrm{dm}^{3}$, referred to biphasic $\mathrm{IO} / \mathrm{H}_{2} \mathrm{O}$ solvent system. Before the hydrogenation experiment the catalyst, wetted with water, is activated inside the reactor in a flow of hydrogen for $45 \mathrm{~min}$ at $20^{\circ} \mathrm{C}$ and $45 \mathrm{~min}$ at the temperature of reaction $\left(40^{\circ} \mathrm{C}\right)$. For comparison, in hydrogenation tests isooctane or ethanol are used as a single solvent. In the course of catalytic runs the samples of reaction mixture (organic phase) are periodically withdrawn and analyzed by GC method [30]. The contents of $\mathrm{ACT}, \mathrm{PE}, \mathrm{CMK}$, and $\mathrm{CE}$ are determined by comparison with calibration curves. From the data of GC analysis acetophenone conversion $(\mathrm{C}, \%)$ and selectivity $[\mathrm{S}(\mathrm{i})]$ to products, 1-phenylethanol $[\mathrm{S}(\mathrm{PE})]$, cyclohexyl methyl ketone $[\mathrm{S}(\mathrm{CMK})]$ and 1-cyclohexylethanol $[\mathrm{S}(\mathrm{CE})]$ are calculated from the equations:

$\mathrm{C}[\%]=n^{0}(\mathrm{ACT})-n^{\mathrm{t}}(\mathrm{ACT}) / n^{0}(\mathrm{ACT})$

$\mathrm{S}(i)[\%]=n^{t}\left(\mathrm{~N}_{i}\right) / n^{0}(\mathrm{ACT})-n^{t}(\mathrm{ACT})$

where, $n^{0}$ (ACT) and $n^{t}(\mathrm{ACT})$ are the moles of acetophenone initially present in the reactor and the moles of ACT remaining at time $t$, respectively; $n^{t}\left(\mathrm{~N}_{i}\right)$ are number of moles of individual reaction products, $\mathrm{PE}, \mathrm{CMK}, \mathrm{CE}$, at reaction time $t$.

\subsection{Determination of the Partitioning of Reaction Mixture}

In two-phase isooctane-water system the distribution of all the reagents (ACT, PE, CMK, and $\mathrm{CE}$ ) in both solvent phases is determined by GC method. The known amounts of particular reagents $\left(137 \times 10^{-5} \mathrm{~mol}\right.$ of ACT, $199 \times 10^{-5} \mathrm{~mol}$ of PE, $34 \times 10^{-5} \mathrm{~mol} \mathrm{of} \mathrm{CMK}$, and $43 \times 10^{-5}$ mol of $\mathrm{CE}$ ) are added into $20 \mathrm{~cm}^{3}$ of $\mathrm{IO} / \mathrm{H}_{2} \mathrm{O}$ (1:1 by volume). The whole lot is vigorously mixed with a mechanical shaker for $45 \mathrm{~min}$. The samples of liquids from both phases are withdrawn immediately after the completion of shaking, and after 5, 15, 30, and $60 \mathrm{~min}$. The concentrations of ACT, PE, CMK, and CE in both isooctane and aqueous phases are determined using GC method. The equilibrium concentrations of ACT, PE, CMK, and CE are established just after stopping the mixing. The isooctane phase (top layer) contains $92.7 \%$ of ACT, $55.6 \%$ of PE, $100 \%$ of CMK, and $93.0 \%$ of CE. From these data the 
distribution coefficients: 1.08 for ACT and CE, and 1.80 for $\mathrm{PE}$ are calculated and used for the determination of the total concentrations of reagents during the catalytic test on the basis of GC analysis of organic phase only.

\section{Results and Discussion}

\subsection{Characterization of $\mathrm{Ru} / \mathrm{FCN}$ Catalysts}

Preparation and characterization of $\mathrm{Ru} / \mathrm{FCN}$ composites used in the present study in the capacity of catalysts is described in detail in our previous work [30]. Briefly, the results obtained by number of techniques (FT-IR, XPS, DSC, SEM, EDS) show that functional groups of FCN polymer, in particular the amine groups $-\mathrm{NH}$, and $-\mathrm{NH}_{2}$, participate in the coordination of $\mathrm{Ru}(\mathrm{III})$ ions. The coordination sphere of ruthenium trapped within the FCN matrix contains both $\mathrm{Cl}$ and $\mathrm{N}$-ligands in various proportions depending on Ru loading in the polymer. Introductory catalytic experiments show no hydrogenation of ACT when as-prepared $\mathrm{Ru} / \mathrm{FCN}$ composites are tested. In the presence of $\mathrm{NaBH}_{4}$ reduced $2 \% \mathrm{Ru} / \mathrm{FCN}$ catalyst hydrogenation of ACT is effective, however only when reaction is performed in biphasic $\mathrm{IO} / \mathrm{H}_{2} \mathrm{O}$ solvent system. On the other hand, in ethanol, THF, or isooctane as the only solvent the reaction is very slow, practically no measurable under conditions of catalytic tests [30]. Therefore present studies are undertaken to shed more light on the advantageous role of biphasic $\mathrm{IO} / \mathrm{H}_{2} \mathrm{O}$ solvent system in the hydrogenation of ACT. Here, reaction is studied in the presence of reduced $\mathrm{Ru} / \mathrm{FCN}$ catalysts and for the comparison $2 \% \mathrm{Ru} / \mathrm{Al}_{2} \mathrm{O}_{3}$ catalyst is tested.

Ru-particles in reduced Ru/FCN catalysts are characterized by XRD and electron microscopy (SEM and TEM) techniques. The SEM studies are carried out in SEI and BSE (COMPO) modes. SEI (secondary electron imaging) is appropriate for studying the morphology of catalyst. The BSE (COMPO) registration mode provides information about the distribution of $\mathrm{Ru}$ in the catalyst because the brightness observed in BSE images is strongly related to atomic number. BSE (COMPO) images of reduced $\mathrm{Ru} / \mathrm{FCN}$ composites with 1,2 and $4 \mathrm{wt} \% \mathrm{Ru}$ are displayed in Fig. 1. A number of irregular "bright" spots of various shapes and sizes randomly oriented and distributed throughout the polymer beads can be observed in all catalysts. However, no reflections associated with the particles of crystalline Ru appear in their XRD diffraction pattern (Fig. 2a). Thus, irregularly shaped "bright" spots observed in BSE images may be considered to be associated with the presence of aggregated nano-particles of ruthenium. In order to clarify this supposition, the "areas of bright spots" are examined at higher magnification and
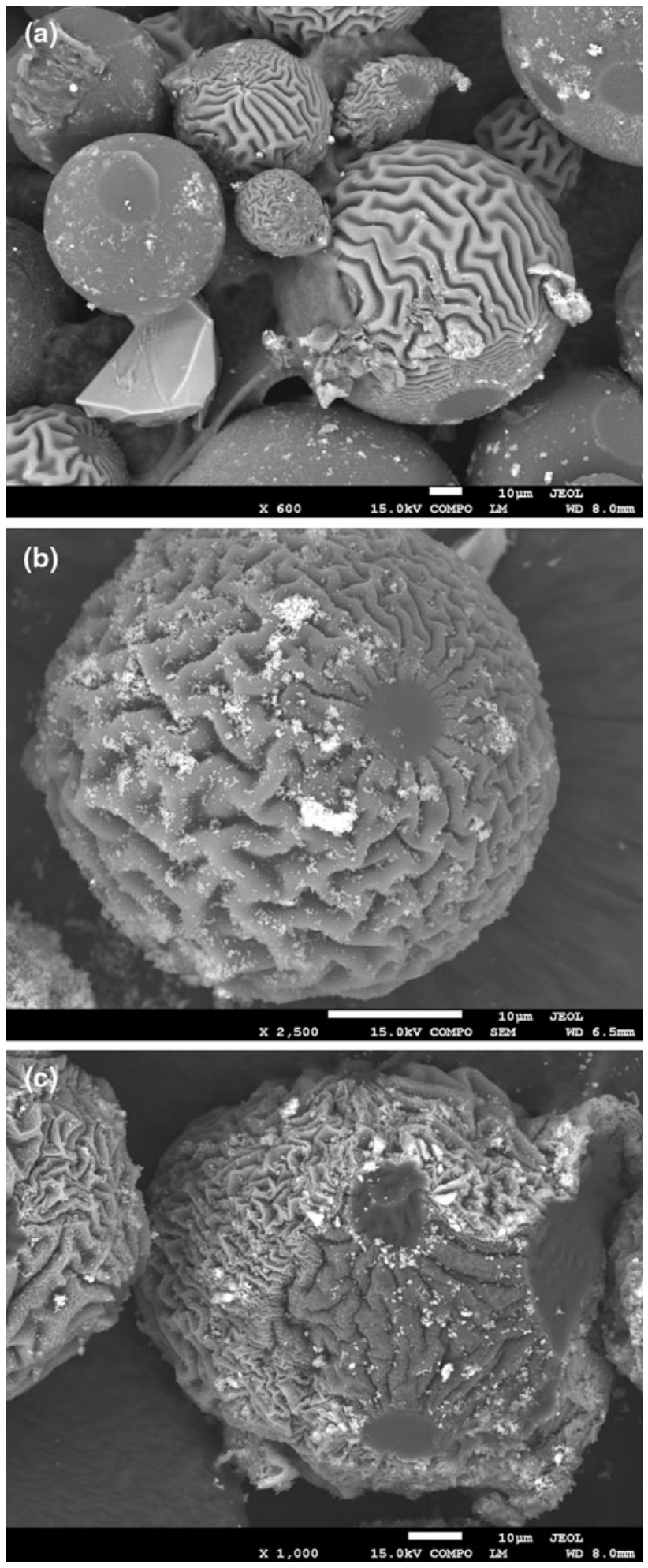

Fig. 1 Electron microscope images (BSE registration mode) of (a) $1 \% \mathrm{Ru} / \mathrm{FCN}$, (b) $2 \% \mathrm{Ru} / \mathrm{FCN}$, and (c) $4 \% \mathrm{Ru} / \mathrm{FCN}$ catalysts

the representative SEI and BSE images are shown in Fig. 3. The SEI image (Fig. 3a) shows that polymer is composed of almost spherical grains of similar shape and size within the range $100-150 \mathrm{~nm}$. The BSE (COMPO) 

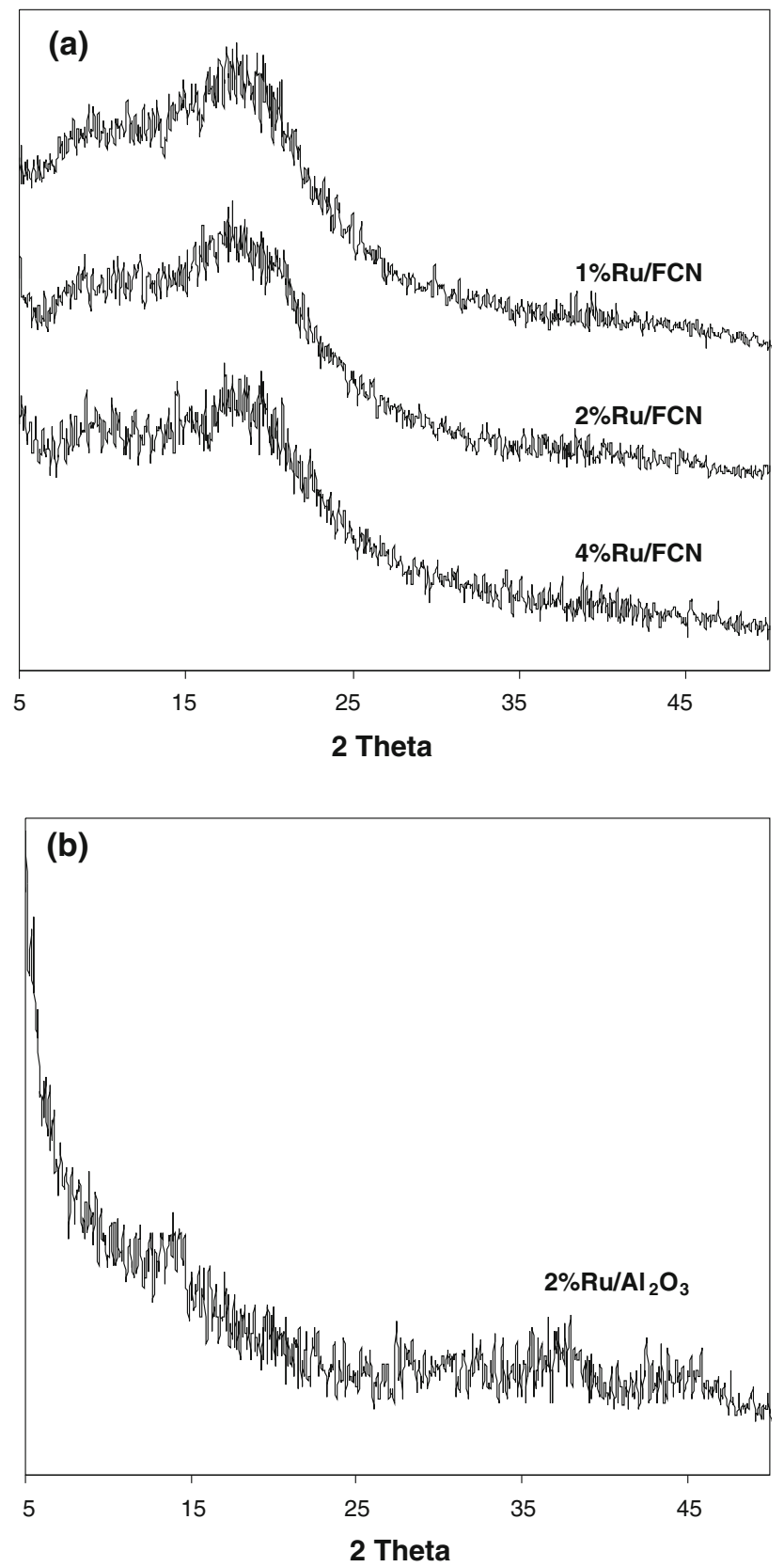

Fig. 2 XRD diffraction pattern of $\mathrm{Ru} / \mathrm{FCN}$ (a) and $2 \% \mathrm{Ru} / \mathrm{Al}_{2} \mathrm{O}_{3}$ (b) catalysts

image (Fig. 3b) reveals that, among spherical polymer grains, agglomerates of much brighter grains exist, which indicates that the concerned areas are substantially enriched in ruthenium.

The nature of $\mathrm{Ru}$ particles in catalysts of various Ru-content is characterized by the STEM micrographs in which ruthenium particles appear as bright spots and/or areas against darker background originating from the polymer matrix (Figs. 4 and 5). At the lowest Ru loading in polymer, $1 \% \mathrm{Ru} / \mathrm{FCN}$ (Fig. 4), no separated particles of Ru can be distinguished but the whole polymer matrix appears

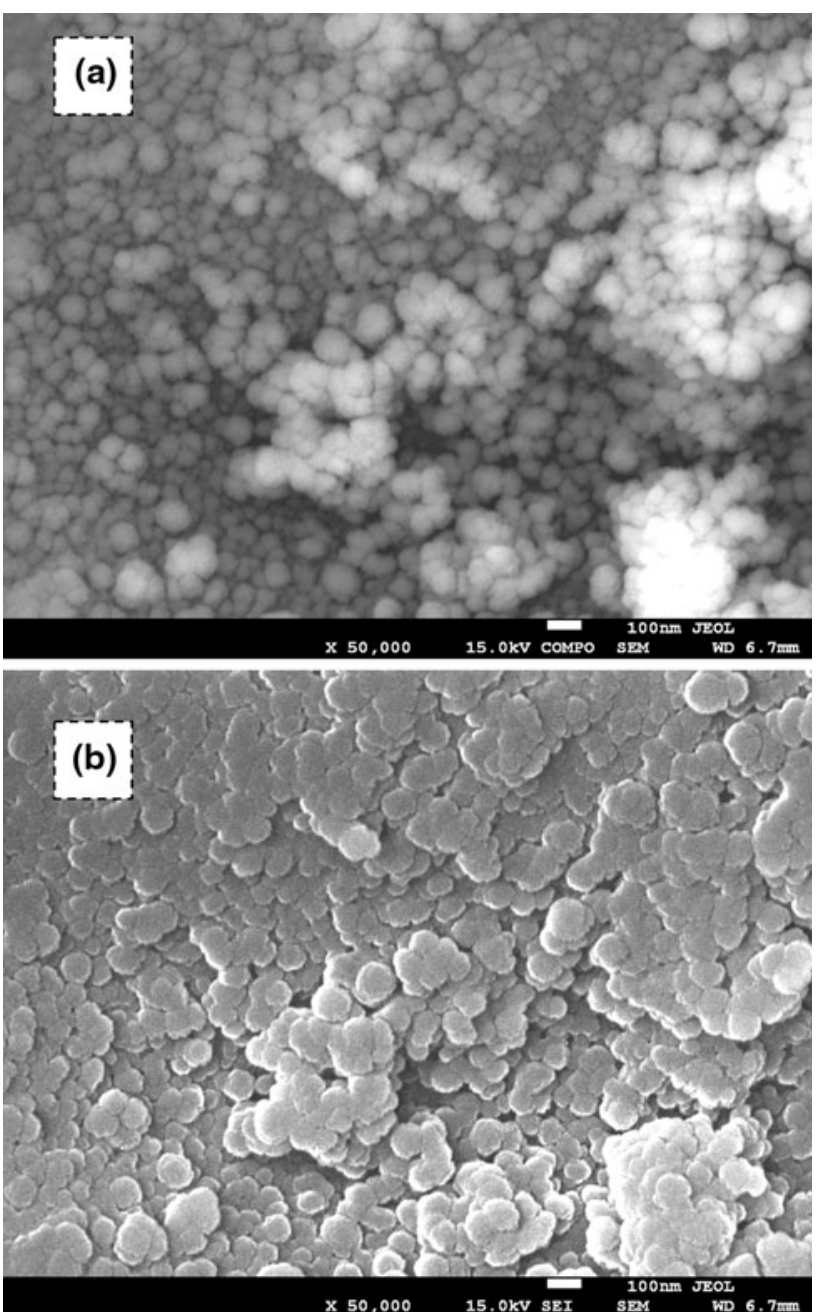

Fig. 3 The BSE (a) and SEI (b) micrographs of $1 \% \mathrm{Ru} / \mathrm{FCN}$

much brighter. Upon increasing Ru loading up to $2 \mathrm{wt} \%$ $\mathrm{Ru}$, apart from "bright areas of polymer" the separated bright spots can be observed showing that ruthenium aggregates start to form. EDS analysis of Ru carried out in marked boxes $(1,2,3)$ indicates the presence of ruthenium even in the areas apparently almost free of bright spots. However, electron diffraction shows no evidence of any crystalline Ru phase in both $1 \% \mathrm{Ru} / \mathrm{FCN}$ and $2 \% \mathrm{Ru} / \mathrm{FCN}$ catalysts, which points to the presence of Ru-containing nano-clusters.

STEM image of catalyst with high Ru loading, 4\% Ru/ FCN, shows a qualitative difference (Fig. 5). Clearly observable bright spots of metallic ruthenium are visible (Fig. 5a) and the electron diffraction pattern originating from crystalline ruthenium (Fig. 5b) is obtained. Although the size of such Ru-crystalline particles is within wide range, their sizes do not exceed few nanometers. Thus, upon increasing ruthenium loading in the FCN polymer the nature of Ru-particles is changed from very highly dispersed Ru-nanoclusters to nanocrystallites of few 

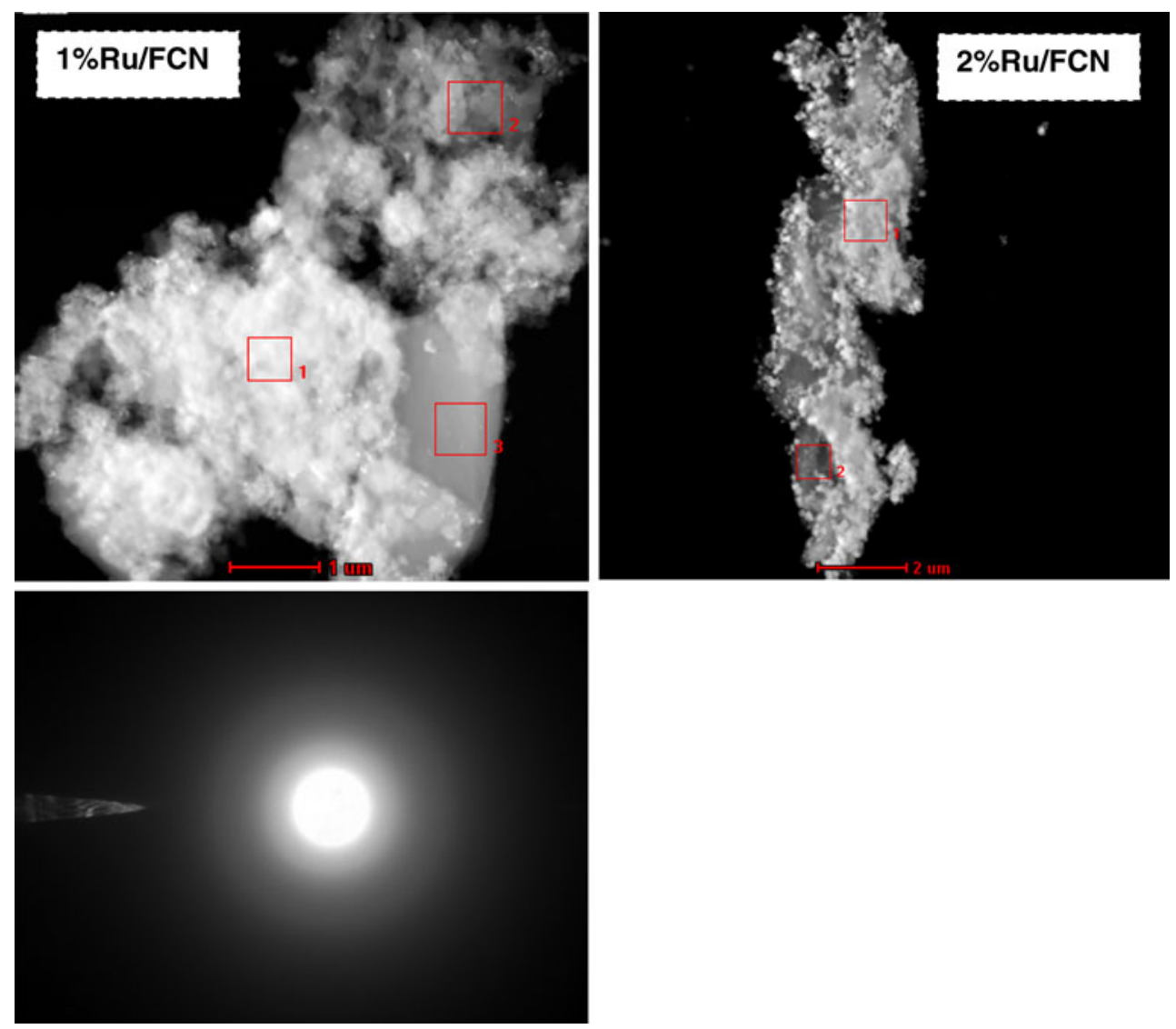

Fig. 4 STEM micrograph of $1 \% \mathrm{Ru} / \mathrm{FCN}$ and $2 \% \mathrm{Ru} / \mathrm{FCN}$ catalysts and electron diffractions

nanometers in size. This may be explained taking into account that amine $-\mathrm{NH}$, and $-\mathrm{NH}_{2}$ groups of $\mathrm{FCN}$ resin (Scheme 2) participate in the immobilization of $\mathrm{Ru}(\mathrm{III})$ ions. In the coordination sphere of $\mathrm{Ru}(\mathrm{III})$-species immobilized by $\mathrm{FCN}$ resin both $\mathrm{Cl}$ and $\mathrm{N}$-ligands are observed, however in various proportions depending on the Ru content introduced into polymer [30]. At low loading of Ru (1 and $2 \mathrm{wt} \%$ ) the contribution of $\mathrm{N}$-groups of polymer in the coordination sphere of Ru-species is high and it decreases as the loading of Ru grows to $4 \mathrm{wt} \%$. In catalysts with low $\mathrm{Ru}$ content (1 and $2 \mathrm{wt} \%$ ) highly dispersed Ru-nanoclusters are observed showing that high contribution of $\mathrm{N}$-groups of polymer in the $\mathrm{Ru}$-species favors the formation of highly dispersed Ru catalysts. On the other hand, functional groups may affect the electron properties of $\mathrm{Ru}$-centers and in consequence catalytic properties of $\mathrm{Ru} / \mathrm{FCN}$ samples. The influence of functional groups, however, would be to some extent determined by the size of Ru-particles. It may be expected that the higher $\mathrm{Ru}$ dispersion, the more important effect of functional groups of polymer matrix.

The electron microscopic images of $2 \% \mathrm{Ru} / \mathrm{Al}_{2} \mathrm{O}_{3}$ catalyst are displayed in Fig. 6. The "white spots" of Ru particles of various shapes and size are observed. Only a few isolated "white spots" appear whereas most of them form aggregates of size within the range 10-50 nm. In the XRD diffraction pattern of $2 \% \mathrm{Ru} / \mathrm{Al}_{2} \mathrm{O}_{3}$ the broad and low intense reflexes of crystalline $\mathrm{Ru}$ located at $38.1^{\circ}$ and $41.1^{\circ}$ appear (Fig. 2b) indicating the presence Ru particles of size of few nanometers. Thus, the "white spots" observed in the SEM micrograph are the aggregated nanoparticles of metallic Ru.

\subsection{Catalytic Experiments}

\subsubsection{Hydrogenation of ACT in the Presence of $2 \% \mathrm{Ru} / \mathrm{Al}_{2} \mathrm{O}_{3}$ Reference Catalyst}

The first part of present work concentrates on ACT hydrogenation in the presence of $2 \% \mathrm{Ru} / \mathrm{Al}_{2} \mathrm{O}_{3}$ catalyst. Reaction is studied in ethanol and isooctane as the only solvents and then in biphasic $\mathrm{IO} / \mathrm{H}_{2} \mathrm{O}$ solvent system. In all experiments the same catalyst concentration $\left(10 \mathrm{~g} / \mathrm{dm}^{3}\right)$ is used. At this amount of catalyst no hydrogenation of ACT is observed in isooctane solvent whereas reaction is effective in ethanol and $\mathrm{IO} / \mathrm{H}_{2} \mathrm{O}$ solvent system. The conversions of ACT obtained in ethanol and in biphasic $\mathrm{IO} / \mathrm{H}_{2} \mathrm{O}$ solvents are compared in Fig. $7 \mathrm{a}$, and the 

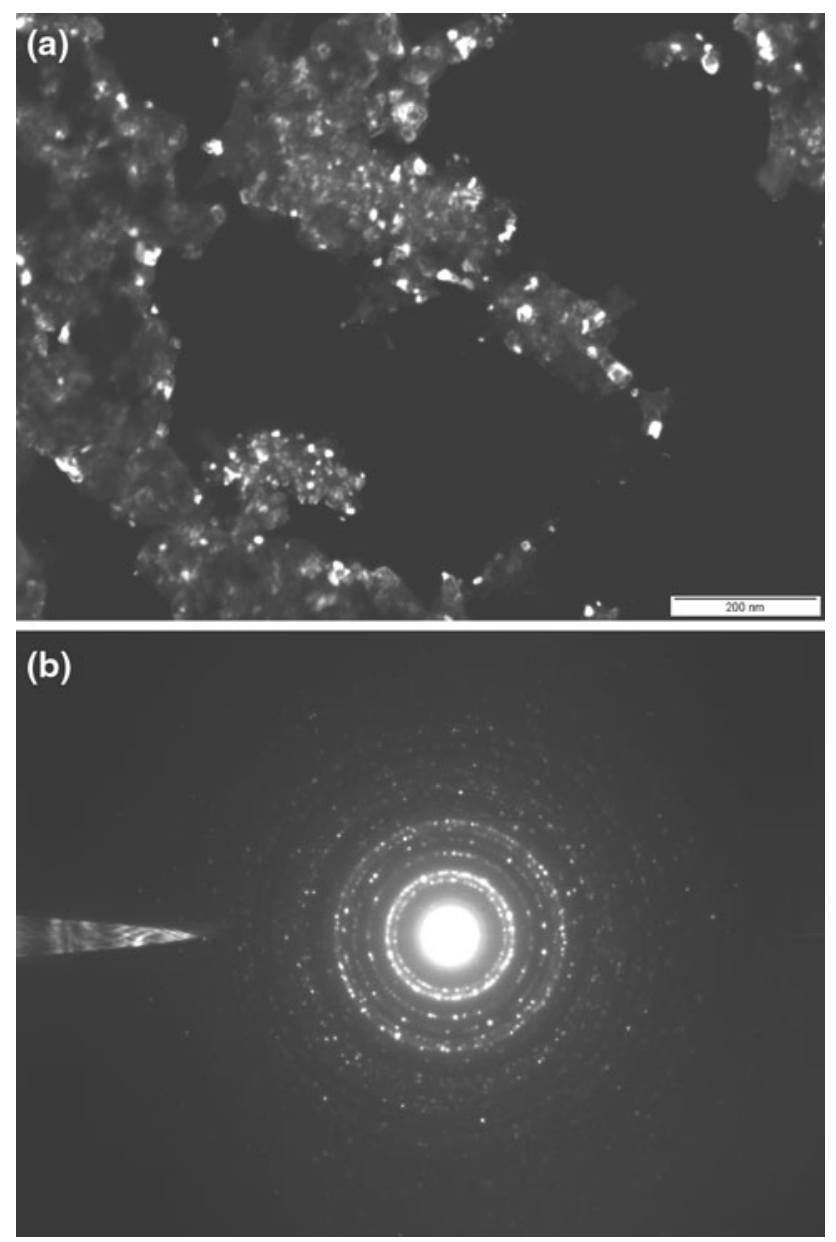

Fig. 5 STEM micrograph of $4 \% \mathrm{Ru} / \mathrm{FCN}$ (a) and electron diffraction (b)

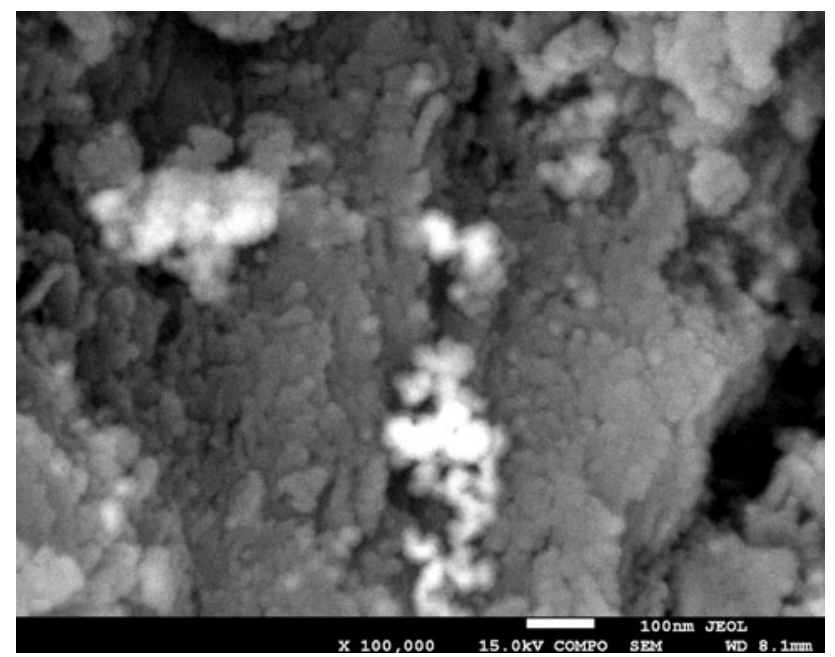

Fig. 6 Electron microscope images (BSE registration mode) of $2 \% \mathrm{Ru} / \mathrm{Al}_{2} \mathrm{O}_{3}$ catalyst

selectivities to PE, CMK and CE are reported in Fig. 7b. In ethanol solvent, the hydrogenation of ACT is effective, but the reaction proceeds at a very low rate and about $20 \%$
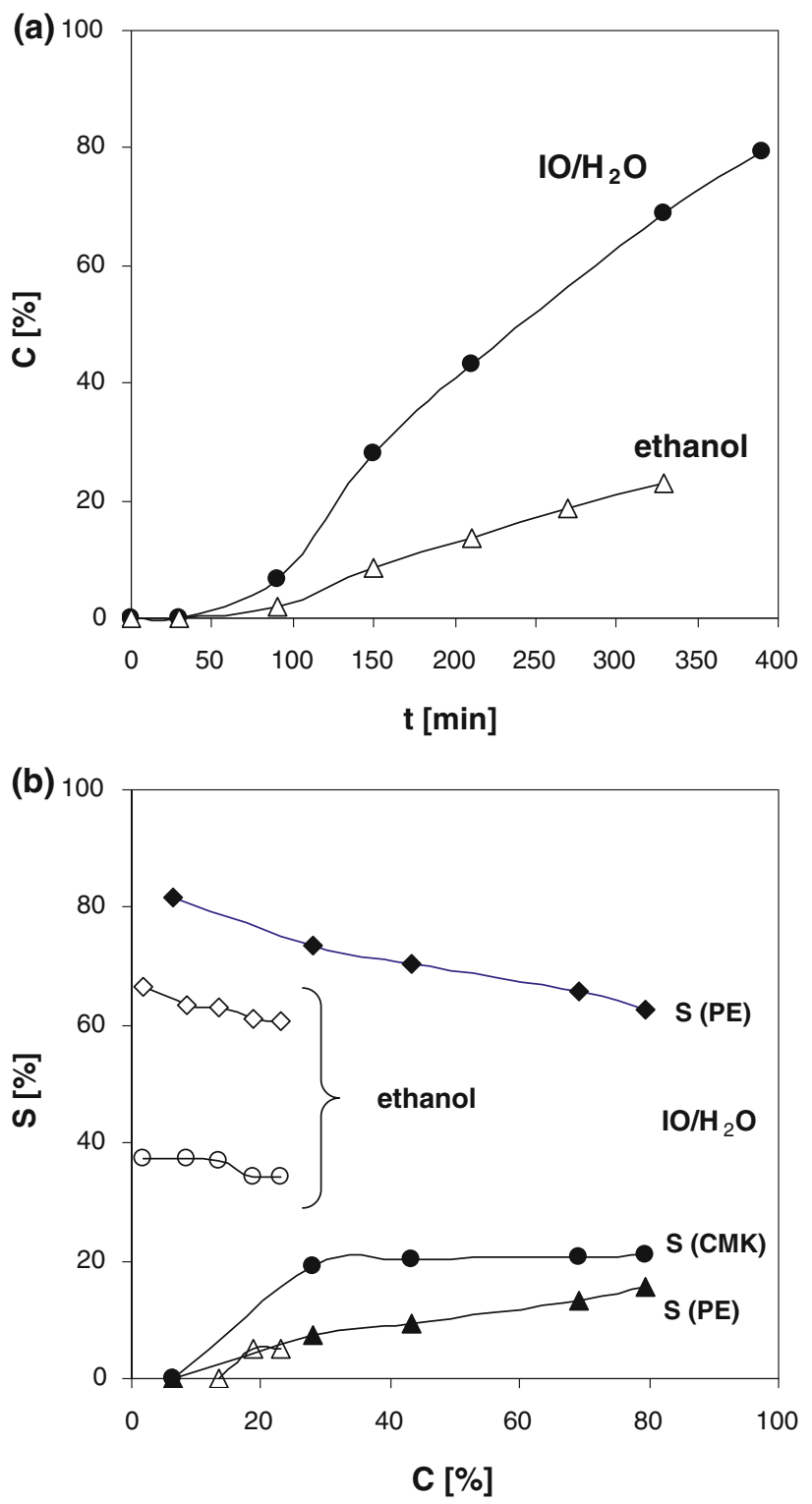

Fig. 7 Hydrogenation of ACT in the presence of $2 \% \mathrm{Ru} / \mathrm{Al}_{2} \mathrm{O}_{3}$ in ethanol and biphasic $\mathrm{IO} / \mathrm{H}_{2} \mathrm{O}$ solvent system. Conversion of ACT vs. reaction time (a) and selectivity to particular reaction products against ACT conversion (b), (catalyst concentration $10 \mathrm{~g} / \mathrm{dm}^{3}$, ACT: $0.137 \mathrm{~mol} / \mathrm{dm}^{3}$ )

ACT conversion is attained after ca. 320 min of reaction. The rate of ACT hydrogenation distinctly grows in biphasic $\mathrm{IO} / \mathrm{H}_{2} \mathrm{O}$ solvent system and after comparable reaction time (ca $300 \mathrm{~min}$ ) almost $70 \%$ of ACT conversion is attained. Furthermore, induction periods appear, especially clearly observable in $\mathrm{IO} / \mathrm{H}_{2} \mathrm{O}$ solvents system. It should be stressed that in the case of ruthenium catalysts induction periods are quite common, especially in reactions carried out at low hydrogen pressure in nonaqueous media. At high hydrogen pressures, induction periods rarely occur, regardless of solvent used [34]. 
A substantial difference can be seen regarding the selectivity of ACT hydrogenation (Fig. 7b). In reaction media, ethanol and $\mathrm{IO} / \mathrm{H}_{2} \mathrm{O}$ solvent system, ACT is hydrogenated via both reaction pathways. The reduction of $\mathrm{C}=\mathrm{O}$ to form phenylethanol (PE) as well as the hydrogenation of aromatic ring yielding cyclohexyl methyl ketone (CMK) take place (Scheme 1). Moreover, 1-cyclohexyl ethanol is also formed. In both solvent systems, the reduction of $\mathrm{C}=\mathrm{O}$ predominates over the hydrogenation of aromatic ring, and this predomination is much higher in biphasic $\mathrm{IO} / \mathrm{H}_{2} \mathrm{O}$ solvent system. In ethanol, selectivity to PE attain ca. $60 \%$ and that to CMK is ca. $40 \%$ (Fig. 7b). Owing to low rate of ACT conversion in ethanol, the data are obtained at ca. $40 \%$ conversion of ACT only. This selectivity pattern in ethanol solvent is similar to that reported by Cerveny et al. [12] who demonstrated comparable selectivities to $\mathrm{PE}$ and $\mathrm{CMK}$ on $5 \% \mathrm{Ru} / \mathrm{Al}_{2} \mathrm{O}_{3}$ catalyst.

On the other hand, in $\mathrm{IO} / \mathrm{H}_{2} \mathrm{O}$ solvent system the rate of ACT conversion is distinctly higher and the raction is studied up to almost complete conversion of ACT. In such biphasic $\mathrm{IO} / \mathrm{H}_{2} \mathrm{O}$ solvent system selectivity to $\mathrm{PE}$ is much higher compared to that of CMK. Selectivity to PE as high as ca. $80 \%$ is reached at the beginning of the reaction. However, as the reaction progresses the selectivity to $\mathrm{PE}$ slowly but continuously decreases whereas the selectivity to 1-cyclohexylethanol (CE) grows. This may suggest that as $\mathrm{PE}$ is formed, it is consumed via hydrogenation of aromatic ring to form 1-cyclohexylethanol (CE). As Fig. $7 \mathrm{~b}$ shows, selectivity to CMK is only $20 \%$ and practically does not change up to the almost complete conversion of ACT. This indicates that only $20 \%$ from the reacted ACT is transformed via aromatic ring hydrogenation whereas $80 \%$ is reacted via $\mathrm{C}=\mathrm{O}$ reduction. Thus, in biphasic $\mathrm{IO} / \mathrm{H}_{2} \mathrm{O}$ system the rate of ACT hydrogenation and the selectivity to $\mathrm{PE}$ are higher compared to the reaction in ethanol. This reveals promoting effect of biphasic IO/ $\mathrm{H}_{2} \mathrm{O}$ solvent system in activity of $2 \% \mathrm{Ru} / \mathrm{Al}_{2} \mathrm{O}_{3}$ and in selective reduction of $\mathrm{C}=\mathrm{O}$ in $\mathrm{ACT}$ to give 1-phenylethanol (PE).

\subsubsection{Hydrogenation of ACT in the Presence of Ru/FCN Catalysts}

The conversion of ACT in the presence of $\mathrm{Ru} / \mathrm{FCN}$ catalysts is displayed in Fig. 8a. Reaction is studied at catalyst concentration of $10 \mathrm{~g} / \mathrm{dm}^{3}$. Under such conditions the activity of $1 \% \mathrm{Ru} / \mathrm{FCN}$ is very low and only $2 \%$ of ACT conversion is achieved after $300 \mathrm{~min}$ of reaction time (data not shown). The hydrogenation of ACT over $2 \% \mathrm{Ru} / \mathrm{FCN}$ and $4 \% \mathrm{Ru} / \mathrm{FCN}$ catalysts is much more effective, the activity of $4 \% \mathrm{Ru} / \mathrm{FCN}$ being distinctly higher than that of $2 \% \mathrm{Ru} / \mathrm{FCN}$. A different "shape" of conversion plots and,
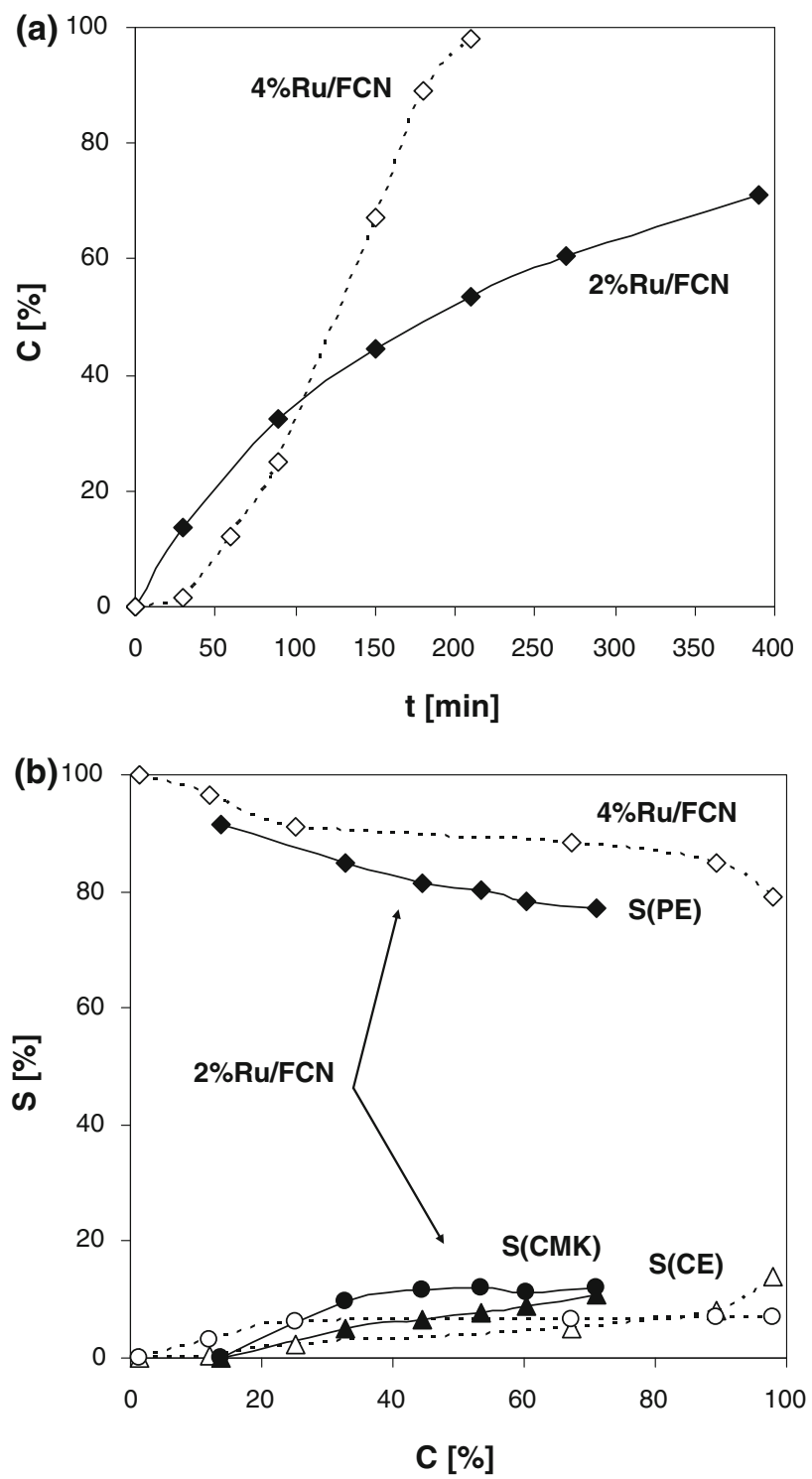

Fig. 8 Hydrogenation of ACT in the presence of $2 \% \mathrm{Ru} / \mathrm{FCN}$ and $4 \% \mathrm{Ru} / \mathrm{FCN}$ catalysts in biphasic $\mathrm{IO} / \mathrm{H}_{2} \mathrm{O}$ solvent system. Conversion of ACT vs. reaction time (a) and selectivity to particular reaction products against ACT conversion (b) (catalyst concentration $10 \mathrm{~g} / \mathrm{dm}^{3}$, ACT: $0.137 \mathrm{~mol} / \mathrm{dm}^{3}$ )

in particular, a pronounced induction period observed in the presence of $4 \% \mathrm{Ru} / \mathrm{FCN}$ makes difficult calculation and comparison of reaction rates. Selectivity patterns (Fig. 8b) shows that on both $\mathrm{Ru} / \mathrm{FCN}$ catalysts ACT is preferentially transformed via hydrogenation of $\mathrm{C}=\mathrm{O}$ to give unsaturated alcohol, PE. The selectivity to CMK is only ca. $11-12 \%$ on $2 \% \mathrm{Ru} / \mathrm{FCN}$ and slightly lower $6-7 \%$ on $4 \% \mathrm{Ru} / \mathrm{FCN}$ catalyst. Similarly to $2 \% \mathrm{Ru} / \mathrm{Al}_{2} \mathrm{O}_{3}$, the selectivity to $\mathrm{CMK}$ is practically stable up to almost complete conversion of $\mathrm{ACT}$. As the reaction progresses the selectivity to PE slowly decreases whereas that of CE grows. Thus, polymer supported $\mathrm{Ru} / \mathrm{FCN}$ catalysts show clear preference for catalyzing $\mathrm{C}=\mathrm{O}$ reduction rather than hydrogenation of 
phenyl ring, and this preference is somewhat stronger for the $4 \% \mathrm{Ru} / \mathrm{FCN}$ catalyst. This may be associated with the differences in the nature of Ru particles in both catalysts. In $2 \% \mathrm{Ru} / \mathrm{FCN}$ catalyst ruthenium exists mainly in the form of well dispersed nano-clusters, while in $4 \% \mathrm{Ru} / \mathrm{FCN}$ catalyst, Ru particles, although still not larger than few nanometers, exhibit crystalline character. Moreover, in the presence of both $2 \% \mathrm{Ru} / \mathrm{FCN}$ and $4 \% \mathrm{Ru} / \mathrm{FCN}$ catalysts, predomination of $\mathrm{C}=\mathrm{O}$ reduction over aromatic ring hydrogenation is higher compared to that of $2 \% \mathrm{Ru} / \mathrm{Al}_{2} \mathrm{O}_{3}$.

The effect of $4 \% \mathrm{Ru} / \mathrm{FCN}$ catalyst concentration $\left(7.5-12.5 \mathrm{~g} / \mathrm{dm}^{3}\right)$ is shown in Fig. 9. Within the whole
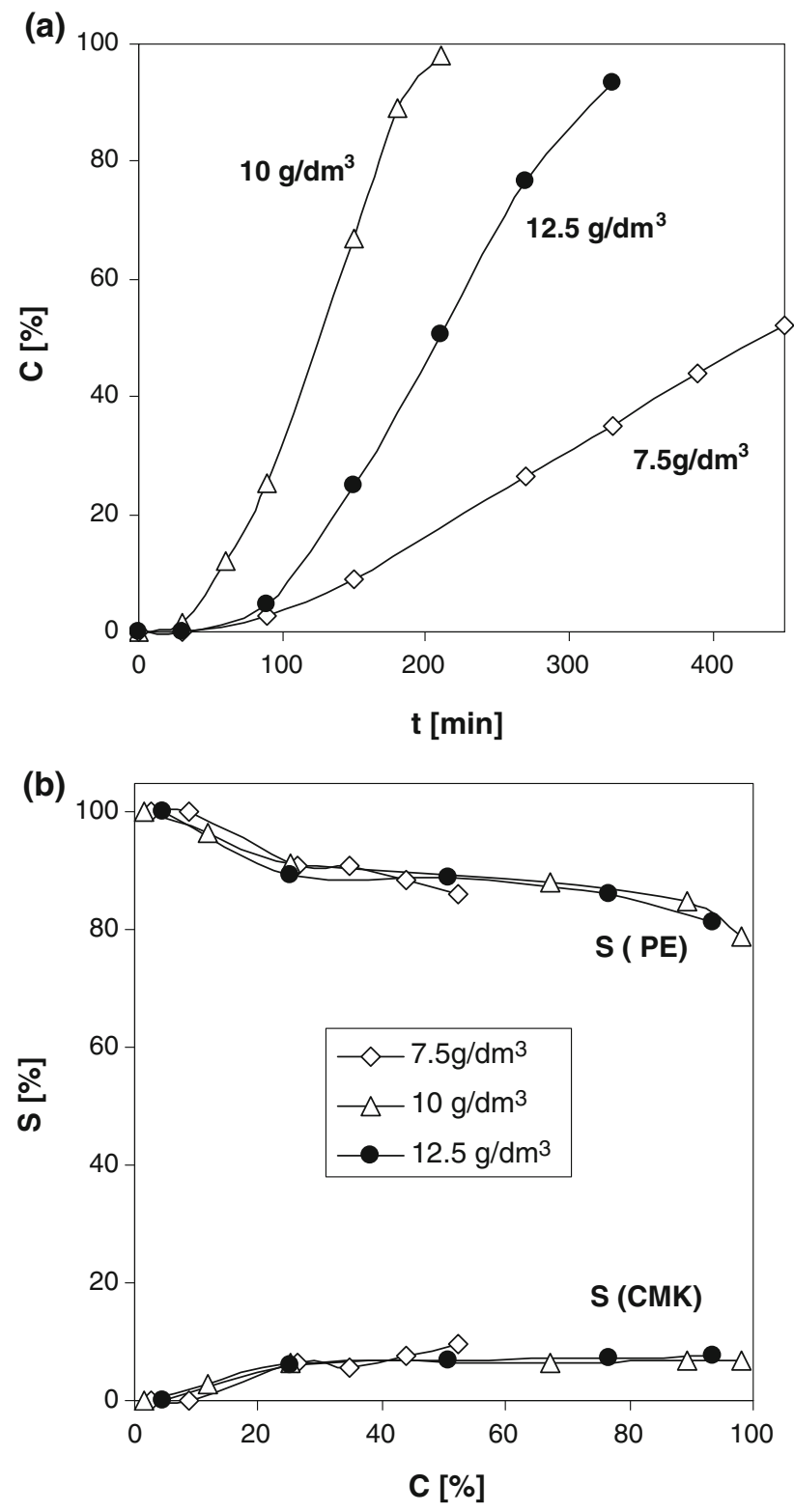

Fig. 9 The effect of $4 \% \mathrm{Ru} / \mathrm{FCN}$ catalyst concentration. Conversion of ACT vs. reaction time (a) and selectivity to particular reaction products against ACT conversion (b) (ACT concentration $0.137 \mathrm{~mol} / \mathrm{dm}^{3}$ ) range of catalyst concentration an induction period is observed making the calculation of hydrogenation rate complex (Fig. 9a). Nevertheless, the rate of ACT conversion increases as the concentration of $4 \% \mathrm{Ru} / \mathrm{FCN}$ catalyst grows up to $10 \mathrm{~g} / \mathrm{dm}^{3}$. At higher concentration, $12.5 \mathrm{~g} / \mathrm{dm}^{3}$, the rate decreases, which is most likely associated with limited supply of hydrogen to the catalyst surface. Therefore in all experiments the concentration of catalyst $10 \mathrm{~g} /$ $\mathrm{dm}^{3}$ is used. The concentration of $4 \% \mathrm{Ru} / \mathrm{FCN}$ does not affect the selectivity pattern of ACT hydrogenation (Fig. 9b) because PE is formed as the major product. The selectivity to CMK, product of aromatic ring hydrogenation is very low, ca. $6-7 \%$ and practically does not change during the hydrogenation experiment.

The hydrogenation is also studied using 2-times lower initial ACT concentration (Fig. 10). The induction periods are observed in both solutions but induction period is longer at lower initial ACT concentration. However, both conversion curves vs. reaction time are parallel (Fig. 10), which shows that the rates of ACT conversion do not depend on initial ACT concentration. Moreover, initial ACT concentration does not influence substantially the selectivity of $\mathrm{C}=\mathrm{O}$ reduction, which is still high regardless of initial ACT concentration.

\subsection{Recovery and Reuse}

A frequently encountered problem of polymer supported catalysts is the decrease of their activity due to the leaching of metal particles under catalytic test. In order to determine whether $\mathrm{Ru} / \mathrm{FCN}$ are stable under reaction conditions the $2 \% \mathrm{Ru} / \mathrm{FCN}$ catalyst is recovered and reused twice. After each hydrogenation test, the catalyst is separated by filtration, washed with acetone, dried in air, and then subjected to the next catalytic cycle. Fresh ACT solution is added and the same hydrogenation conditions are applied. The decrease of ACT content (mol \%) against reaction time in the first and the third catalytic runs are practically the same (Fig. 11a). The selectivity to PE as well as to CMK (Fig. 11b) after 3 reaction cycles are the same as those of fresh catalyst showing that high selectivity towards carbonyl group in ACT remains unchanged.

This set of experiments proves stable activity of $2 \% \mathrm{Ru} /$ FCN in recycling hydrogenation experiments which most likely results from the multidentate character of FCN resins (Scheme 2). As mentioned before, in FCN matrix chelating functional groups $\left(-\mathrm{NH},-\mathrm{NH}_{2}, \mathrm{C}=\mathrm{O}\right)$ appear, able to fill coordination sites of ruthenium making the metal centre strongly bound to the support. This is in agreement with the literature data [35] showing that leaching of the metal from the polymer can be reduced significantly by using polymer functionalized by chelating ligands. 

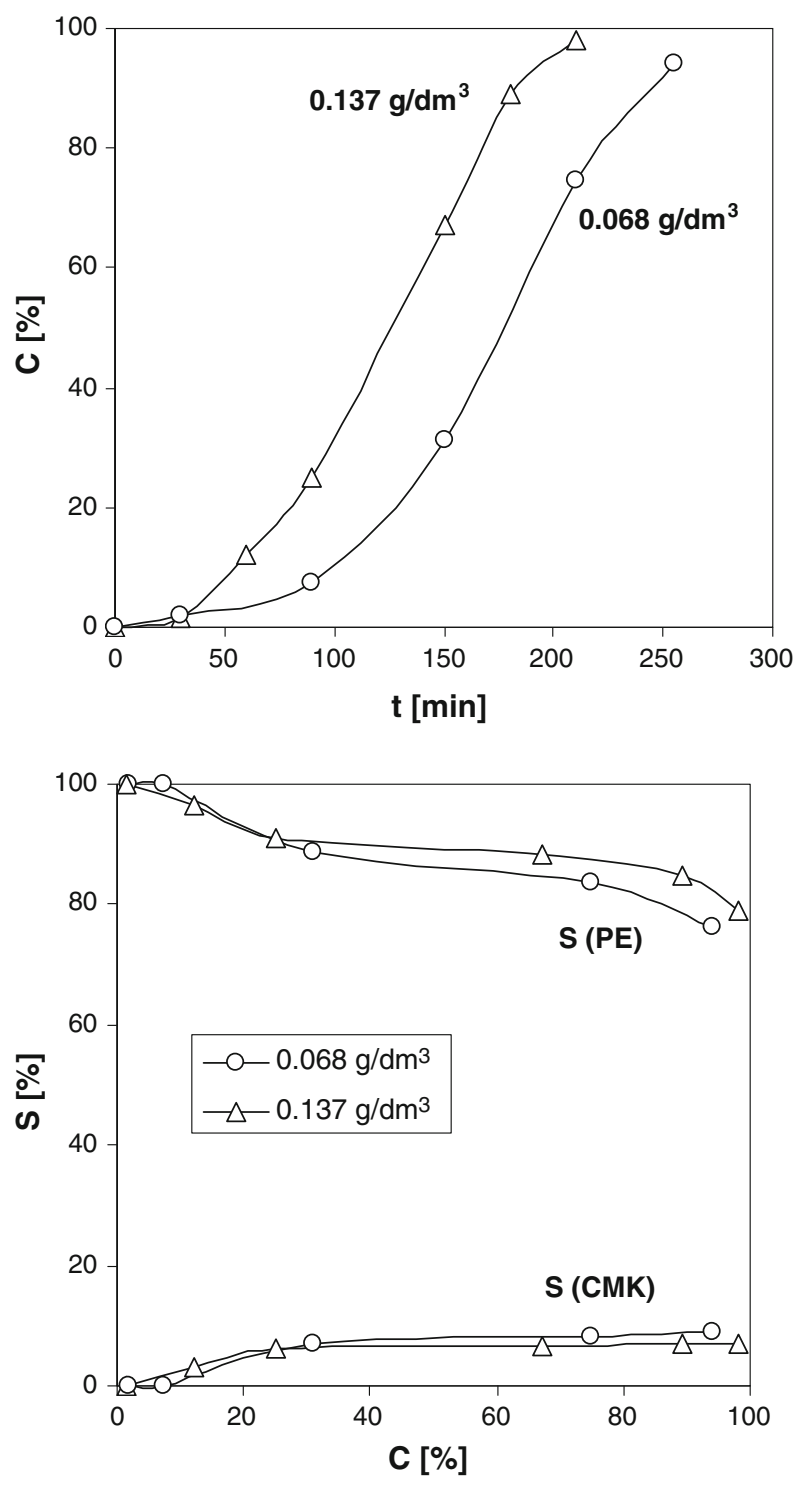

Fig. 10 The effect of initial ACT concentration. Conversion of ACT vs. reaction time and selectivity to particular reaction products against ACT conversion in the presence of $4 \% \mathrm{Ru} / \mathrm{FCN}$ catalyst (catalyst concentration $10 \mathrm{~g} / \mathrm{dm}^{3}$ )

\subsection{The Role of the Bi-phasic Solvent System}

In liquid phase catalytic reactions the type of solvent frequently influences the rate and selectivity of reaction. The effect has usually a complex nature and may be related to reactant-solvent, product-solvent and/or catalyst-solvent interactions $[34,36]$. Often, the solvent effect is rationalized by correlating the reaction rates and product distribution with solvent polarity or dielectric constant [13, 19]. For instance, the activity of $\mathrm{Pd} / \mathrm{AlPO}_{4}$ in hydrogenation of $\mathrm{ACT}$ in various alcohols decreases when increasing the alcohol dielectric constant [18]. Similarly, on Raney Ni catalyst the ACT hydrogenation is faster in cyclohexane
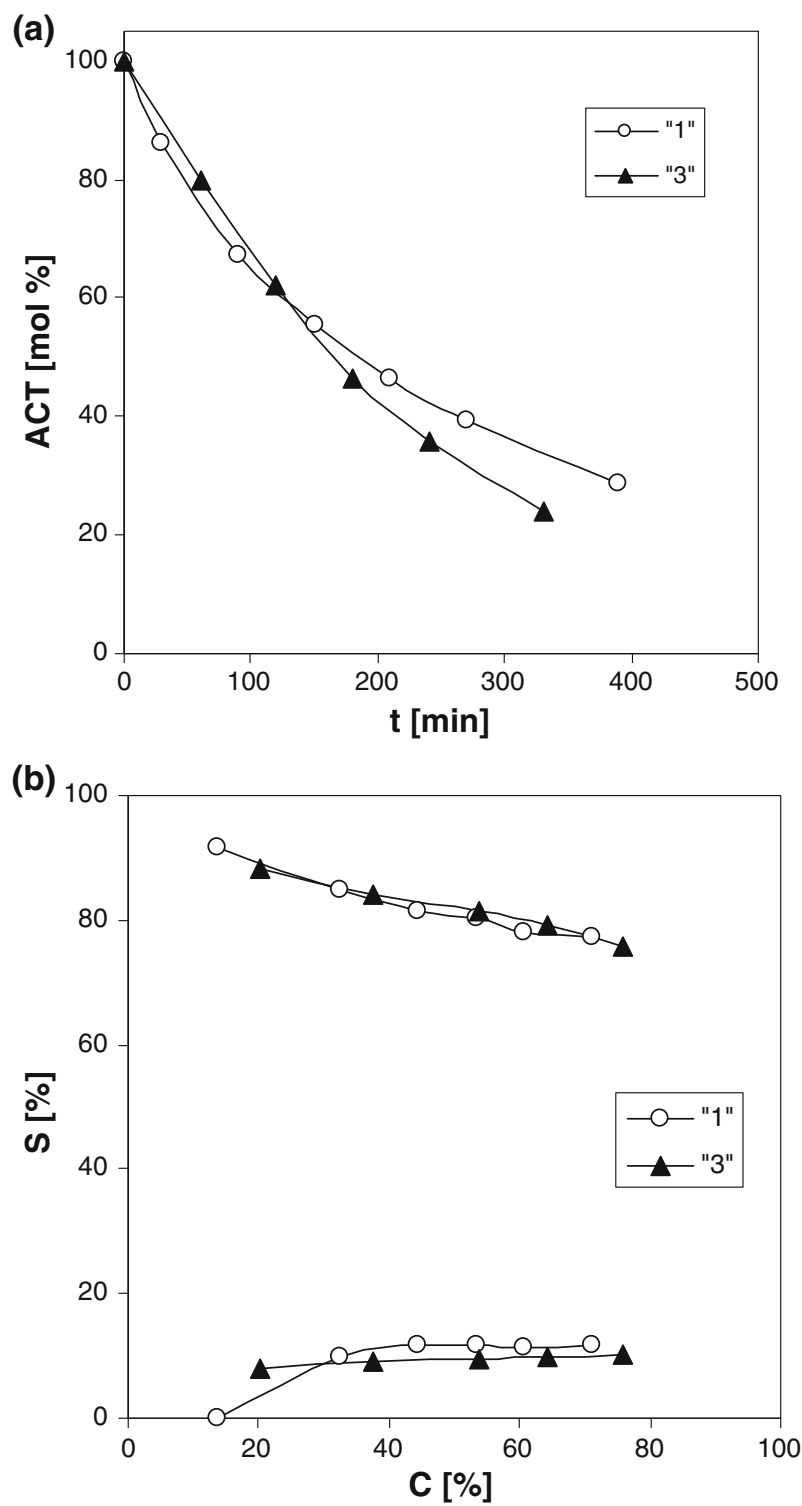

Fig. 11 Successive use of $2 \% \mathrm{Ru} / \mathrm{FCN}$ catalyst in hydrogenation of ACT. The change of ACT content vs. reaction time (a) and selectivity to PE and CMK against conversion of ACT in first ("1") and third ("3") catalytic experiment (b) (catalyst concentration $10 \mathrm{~g} / \mathrm{dm}^{3}$, ACT: $0.137 \mathrm{~mol} / \mathrm{dm}^{3}$ )

than in alcohol solvents [37]. Moreover, apart from polarity of solvents, the nature of support in Pd catalysts is found to affect the rate and selectivity of ACT hydrogenation [38]. Solvent effect can be manifested among others, in interactions with the reactants molecules via the solvation effect. From the experiments of competitive hydrogenation of non-polar and polar substrates, a general conclusion has been formulated, indicating that a polar solvent enhances adsorption of a non-polar reactant at the catalyst surface while a non-polar solvent promotes adsorption of a polar reactant $[34,36]$. Due to such solvent-substrate solvation 
effect, the selectivity and the type of product formed may change significantly. In reactants possessing polar groups, interaction with the solvent can affect different fragments of the molecules, depending on the solvent polarity. The hydrogenation of p-phenylphenol, which contains less polar unsubstituted phenyl ring and more polar OH-substituted phenyl rings, is a good illustration [34]. In the polar water-acetic acid solvents, p-cyclohexylphenol is the major product, because $\mathrm{OH}$-substituted phenolic ring is more strongly solvated and thus less readily adsorbed on the catalyst surface. Conversely, more effective solvation of less polar unsubstituted phenyl ring by less polar cyclohexane solvent resulted in preferential adsorption of $\mathrm{OH}$-substituted phenolic ring and preferential formation of phenylcyclohexanol.

In biphasic $\mathrm{IO} / \mathrm{H}_{2} \mathrm{O}$ system the reduction of $\mathrm{C}=\mathrm{O}$ predominates over the hydrogenation of aromatic ring in the ACT substrate. Moreover, the reaction in biphasic $\mathrm{IO} / \mathrm{H}_{2} \mathrm{O}$ system is faster than in ethanol.

While trying to find a rationale for the observed phenomenon, one should recall that in biphasic $\mathrm{IO} / \mathrm{H}_{2} \mathrm{O}$ solvent system the overwhelming majority of ACT is contained in less polar isooctane. On the other hand, the primary function of the water is believed to be making the surrounding of $\mathrm{Ru}$ centers more hydrophilic, similarly to what is postulated for benzene-water system used for hydrogenation of Ru-supported catalysts [39, 40]. Under such conditions the ACT molecule assumes orientation in which its less polar part, i.e. phenyl ring, is directed towards non-polar isooctane, while the more polar carbonyl group is exposed toward $\mathrm{Ru}$ centers. Additionally, the enhanced hydrophilicity of catalyst surface may facilitate interaction of Ru-centers with the lone pair of the electrons on the carbonyl oxygen, which polarizes the $\mathrm{C}=\mathrm{O}$ bond, and hence promotes its hydrogenation. For the same reason, in biphasic $\mathrm{IO} / \mathrm{H}_{2} \mathrm{O}$ system, the adsorption of ACT molecule at the catalyst surface in a flat configuration, involving simultaneous adsorption of aromatic ring and carbonyl group, is much less likely. Thus, the observed effect of biphasic $\mathrm{IO} / \mathrm{H}_{2} \mathrm{O}$ system can be explained by its role in controlling the orientation of ACT molecule and enhancing the hydrophilicity of the catalyst surface. This favors catalystACT interaction via carbonyl group and preferential reduction of $\mathrm{ACT}$ to $\mathrm{PE}$.

Comparison of the catalytic performance of $\mathrm{Ru} / \mathrm{FCN}$ and $\mathrm{Ru} / \mathrm{Al}_{2} \mathrm{O}_{3}$ catalysts shows that the preference for the selective $\mathrm{C}=\mathrm{O}$ reduction is more pronounced in the presence of FCN polymer-supported Ru. This advantageous effect points to the crucial role of the polymer support. It is likely that the polymer chains surrounding the Ru particles contribute to a desired steric orientation of the ACT reactant.

\section{Conclusions}

Ruthenium catalysts supported on amine functionalized methacrylate-styrene FCN resin prove very active and highly selective in the hydrogenation of carbonyl group in acetophenone. In the presence of $4 \% \mathrm{Ru} / \mathrm{FCN}$ catalyst 1-phenylethanol is formed with ca. $80 \%$ selectivity. The essential feature of the catalytic set-up is the use of a biphasic isooctane/water solvent system. An important aspect of reaction carried out in the biphasic isooctane/ water solvent is that acetophenone becomes transformed preferentially via hydrogenation of $\mathrm{C}=\mathrm{O}$ group rather than hydrogenation of aromatic ring. The role of biphasic isooctane/water solvent system has been attributed to the solvation of acetophenone phenyl ring by non-polar isooctane, which enhances appropriate orientation of the reactant and facilitates adsorption and catalytic transformation of polar carbonyl group at the surface of the catalyst. Superior selectivity to 1-phenylethanol over polymersupported ruthenium catalyst with respect to the reference $\mathrm{Ru} / \mathrm{Al}_{2} \mathrm{O}_{3}$ catalyst is tentatively assigned to steric effects induced by the polymer chains which enhance favorable orientation of acetophenone molecule towards $\mathrm{Ru}$ active sites.

Acknowledgements D. D. acknowledges the financial support from the POL-POST DOC II (project D037/H03/2006) and grant NN204 249034 (project 2490/B/H03/2008/34). The authors thank Prof. W. Bukowski and dr A. Bukowska from Rzeszow University of Technology for preparation of polymeric support.

Open Access This article is distributed under the terms of the Creative Commons Attribution Noncommercial License which permits any noncommercial use, distribution, and reproduction in any medium, provided the original author(s) and source are credited.

\section{References}

1. Blaser H-U, Malan Ch, Pugin B, Spindler F, Steiner H, Studer M (2003) Adv Synth Catal 345:103

2. Wang Ch, Wu X, Xiao J (2008) Chem Asian J 3:1750

3. Noyori R, Ohkuma T (2001) Angew Chem Int Ed 40:40

4. Rajashekharam MV, Bergault I, Fouilloux P, Schweich D, Delmas H, Chaudhari RV (1999) Catal Today 48:83

5. Malyala RV, Rode CV, Arai M, Hedge SG, Chaudhari RV (2000) Appl Catal A 193:71

6. Bergault I, Fouilloux P, Joly-Vuillemin C, Delmas H (1998) J Catal 175:328

7. Bergault I, Joly-Vuillemin C, Fouilloux P, Delmas H (1999) Catal Today 48:161

8. Bertero NM, Apesteguia CR, Marchi AJ (2008) Appl Catal A 349:100

9. Chen CS, Chen HW, Cheng WH (2003) Appl Catal A 248:117

10. Santori GF, Moglioni AG, Vetere V, Moltrasio Iglesias GY, Casella ML, Ferretti OA (2004) Appl Catal A 269:215

11. Kluson P, Cerveny L (1995) Appl Catal A 128:13

12. Cerveny L, Dobrovolna Z, Belohlav Z, Kluson P (1996) Collect Czechoslov Chem Commun 61:764 
13. Drelinkiewicz A, Waksmundzka A, Makowski W, Sobczak JW, Król A, Zięba A (2004) Catal Lett 94:143

14. Lin SD, Sanders DK, Vannice MA (1994) Appl Catal A 113:59

15. Vannice MA (1992) Catal Today 12:255

16. Vannice MA (1997) Top Catal 4:241

17. Meschke RW, Hartung WH (1960) J Org Chem 25:137

18. Aramendia MA, Borau V, Gomez JF, Herrera A, Jimenez C, Marinas JM (1993) J Catal 140:335

19. Aramendia MA, Borau V, Jimenez C, Marinas JM, Sempere ME, Urbano P (1988) Appl Catal 43:41

20. Tundo P, Zinovyev S, Perosa A (2000) J Catal 196:330

21. Kluson P, Cerveny L (1996) J Mol Catal A 108:107

22. Wismeijer AA, Kieboom APG, van Bekkum H (1985) React Kinet Catal Lett 29:311

23. Casagrande M, Storaro L, Talon A, Lenarda M, Frattini R, Rodriguez-Castellon E, Maireles-Torres P (2002) J Mol Catal A 188:133

24. Marques CA, Selva M, Tundo P (1995) J Org Chem 60:2430

25. Tundo P, Perosa A, Zinovyev S (2003) J Mol Catal A 204-205:747

26. Perosa A, Selva M, Tundo P (1999) J Org Chem 64:3934

27. Perosa A, Tundo P, Selva M (2002) J Mol Catal A 180:169

28. Drelinkiewicz A, Stanuch W, Knapik A, Ghanem A, Kosydar R, Bukowska A, Bukowski W (2009) J Mol Catal A 300:8
29. Drelinkiewicz A, Knapik A, Stanuch W, Sobczak J, Bukowska A, Bukowski W (2008) React Funct Polym 68:1650

30. Duraczynska D, Drelinkiewicz A, Serwicka EM, RutkowskaZbik D, Bielańska E, Socha R, Bukowska A, Bukowski W (2010) React Funct Polym 70:382

31. Sanchez-Delago RA, Machalaba N, Ng-a-qui N (2007) Catal Commun 8:2115

32. Hronec M, Cvengrosova Z, Kralik M, Palma G, Corain B (1996) J Mol Catal A 105:25

33. Patel DR, Dalal MK, Ram RN (1996) J Mol Catal A 109:141

34. Rylander PN (1967) Catalytic hydrogenation over platinum metals. Academic Press, New York, p 238

35. Michalska Z, Strzelec K (2001) J Mol Catal A 177:89

36. Singh UK, Vannice MA (2001) Appl Catal A 213:1

37. Masson J, Cividino P, Bonier JM, Fouilloux P (1991) Stud Surf Sci Catal 245

38. Bejblova M, Zamostny P, Cerveny L, Cejka J (2003) Collect Czech Chem Commun 68:1969

39. Struijk J, d'Angremond M, Lucas de Regt WJM, Scholten JJF (1992) Appl Catal A 83:263

40. Milone C, Neri G, Donato A, Musolino MG, Mercadante L (1996) J Catal 159:253 